\title{
Recent Advances of Interventional Endoscopic Retrograde Cholangiopancreatography and Endoscopic Ultrasound for Patients with Surgically Altered Anatomy
}

\author{
Yuki Tanisaka*(D), Masafumi Mizuide, Akashi Fujita (D), Tomoya Ogawa, Masahiro Suzuki, Hiromune Katsuda, \\ Youichi Saito, Kazuya Miyaguchi, Tomoaki Tashima, Yumi Mashimo and Shomei Ryozawa (D)
}

Citation: Tanisaka, Y.; Mizuide, M.; Fujita, A.; Ogawa, T.; Suzuki, M.; Katsuda, H.; Saito, Y.; Miyaguchi, K.; Tashima, T.; Mashimo, Y.; et al. Recent Advances of Interventional

Endoscopic Retrograde

Cholangiopancreatography and Endoscopic Ultrasound for Patients with Surgically Altered Anatomy. J. Clin. Med. 2021, 10, 1624. https:// doi.org/10.3390/jcm10081624

Academic Editor: Saburo Matsubara

Received: 23 February 2021

Accepted: 9 April 2021

Published: 12 April 2021

Publisher's Note: MDPI stays neutral with regard to jurisdictional claims in published maps and institutional affiliations.

Copyright: (c) 2021 by the authors. Licensee MDPI, Basel, Switzerland. This article is an open access article distributed under the terms and conditions of the Creative Commons Attribution (CC BY) license (https:// creativecommons.org/licenses/by/ $4.0 /)$.
Department of Gastroenterology, Saitama Medical University International Medical Center, 1397-1, Yamane, Hidaka, Saitama 350-1298, Japan; mizuide1971@yahoo.co.jp (M.M.); a.fujita0628@gmail.com (A.F.); t.ogawa0210@icloud.com (T.O.); msuzgast@tmd.ac.jp (M.S.); hk0112@saitama-med.ac.jp (H.K.); stm_ys41@yahoo.co.jp (Y.S.); kaz.hr77@gmail.com (K.M.); tomo3029@saitama-med.ac.jp (T.T.); ymashimo@saitama-med.ac.jp (Y.M.); ryozawa@saitama-med.ac.jp (S.R.)

* Correspondence: tanisaka1205@gmail.com; Tel.: +81-42-984-4111

Abstract: Endoscopic retrograde cholangiopancreatography (ERCP) is considered to be the gold standard for diagnosis and interventions in biliopancreatic diseases. However, ERCP in patients with surgically altered anatomy (SAA) appears to be more difficult compared to cases with normal anatomy. Since the production of a balloon enteroscope (BE) for small intestine disorders, BE had also been used for biliopancreatic diseases in patients with SAA. Since the development of BE-assisted ERCP, the outcomes of procedures, such as stone extraction or drainage, have been reported as favorable. Recently, an interventional endoscopic ultrasound (EUS), such as EUS-guided biliary drainage (EUS-BD), has been developed and is available mainly for patients with difficult cases of ERCP. It is a good option for patients with SAA. The effectiveness of interventional EUS for patients with SAA has been reported. Both BE-assisted ERCP and interventional EUS have advantages and disadvantages. The choice of procedure should be individualized to the patient's condition or the expertise of the endoscopists. The aim of this review article is to discuss recent advances in interventional ERCP and EUS for patients with SAA.

Keywords: endoscopic retrograde cholangiopancreatography; altered anatomy; ERCP; balloon enteroscope; single balloon enteroscopy; double balloon enteroscopy; endoscopic ultrasound; EUS; interventional EUS; EUS-BD

\section{Introduction}

There is a large variety of biliary tract diseases, such as bile duct stones and benign/malignant biliary strictures. They lead to hepatobiliary dysfunction, cholangitis, and eventually liver failure requiring appropriate therapy. Since its introduction in 1968, endoscopic retrograde cholangiopancreatography (ERCP) is thought to be the gold standard for diagnosis and interventions in biliopancreatic diseases. It has been reported that ERCP-related procedures have achieved success in approximately 95\% of cases $[1,2]$. However, it is technically challenging to perform ERCP in patients with surgically altered anatomy (SAA), such as Roux-en-Y gastrectomy, hepaticojejunostomy with Roux-en-Y, pancreaticoduodenectomy, or Billroth II gastrectomy. First of all, the afferent limb, increased intestinal curvature, or postoperative adhesions hinder accessibility of the target site, such as the papilla or the hepatico/pancreatojejunal anastomosis. Next, selective biliary cannulation and subsequent procedures, such as stone extraction or drainage, are more difficult in patients with SAA than cases with normal anatomy. Outcomes using a conventional duodenoscope have not been satisfactory [3,4]. Hence, alternative treatments, such as percutaneous transhepatic biliary drainage (PTBD), have been widely applied to 
patients with SAA $[5,6]$. One study from a tertiary referral endoscopy center reported that the afferent loop intubation and cannulation success rates using side-viewing duodenoscope in patients with Billroth II gastrectomy were $86.7 \%$ (618/713 patients) and $93.8 \%$ (580/613 patients). The main reason for intubation failure was a long and angulated afferent loop [7]. Another systematic review and meta-analysis reported that the afferent loop intubation and cannulation success rates using a forward-viewing endoscope in patients with Billroth II gastrectomy were $91.1 \%$ and $92.3 \%$. The subgroup analysis of the forward-viewing endoscope showed that the success rates of afferent loop intubation using the forward-viewing endoscope with cap-fitting $(92.5 \%)$ was higher than the forwardviewing endoscope without cap-fitting $(88.6 \%)$. The success rates of cannulation using the forward-viewing endoscope with cap-fitting $(93.7 \%)$ was higher than the forward-viewing endoscope without cap-fitting (89.2\%) [8]. These studies showed the usefulness of a conventional side or forward-viewing scope in patients with Billroth II gastrectomy. However, these scopes cannot achieve the afferent loop intubation in 10\% of patients due to a long and angulated afferent loop.

Since the introduction of the balloon enteroscope (BE) for small bowel disorders [9], balloon-assisted ERCP, such as single-balloon enteroscopy (SBE)-assisted ERCP, or doubleballoon enteroscopy (DBE)-assisted ERCP, have been developed for patients with SAA. Despite the evident effectiveness of BE-assisted ERCP, it is still more challenging to perform than ERCP in patients with normal anatomy in terms of scope insertion, biliary cannulation, and subsequent diagnostic and interventional procedures, such as forceps biopsy, stone extraction, and stent placement. Recently, interventional endoscopic ultrasound (EUS), such as EUS-guided biliary drainage (EUS-BD) or EUS-guided antegrade intervention, have been available for difficult cases of ERCP, making it a good option for patients with SAA. In this review, we discuss recent advances in interventional ERCP and EUS for patients with SAA.

\section{Balloon Enteroscope}

Table 1 shows the specifications of the SBE and DBE presently available. The BEs are advanced by holding and shortening the intestine with an inflated balloon. The difference of SBE and DBE is the number of balloons (Figure 1). A balloon is attached to the tip of the over-tube for SBE. DBE equips two balloons. One is attached to the tip of the endoscope while another is attached to the tip of the over-tube. Moreover, the working channel port in SBE appears in an $8 o^{\prime}$ clock direction on the endoscopic screen. In contrast, it shows in a 5:30 o'clock direction for DBE.

Table 1. Specifications of single-balloon enteroscopy (SBE) and double-balloon enteroscopy (DBE).

\begin{tabular}{|c|c|c|c|c|}
\hline Company & Olympus & Olympus & Fujifilm & Fujifilm \\
\hline & SIF-Q260 & SIF-H290S & EN-580T & EI-580BT \\
\hline Angle of view & $140^{\circ}$ & $140^{\circ}$ & $140^{\circ}$ & $140^{\circ}$ \\
\hline Outer diameter (mm) & 9.2 & 9.2 & 9.4 & 9.4 \\
\hline Working length (mm) & 2000 & 1520 & 2000 & 1550 \\
\hline Working channel diameter $(\mathrm{mm})$ & 2.8 & 3.2 & 3.2 & 3.2 \\
\hline Passive bending & No & Yes & No & No \\
\hline High-force transmission & No & Yes & No & No \\
\hline The adaptive bending & No & No & No & Yes \\
\hline Advanced force transmission & No & No & No & Yes \\
\hline
\end{tabular}




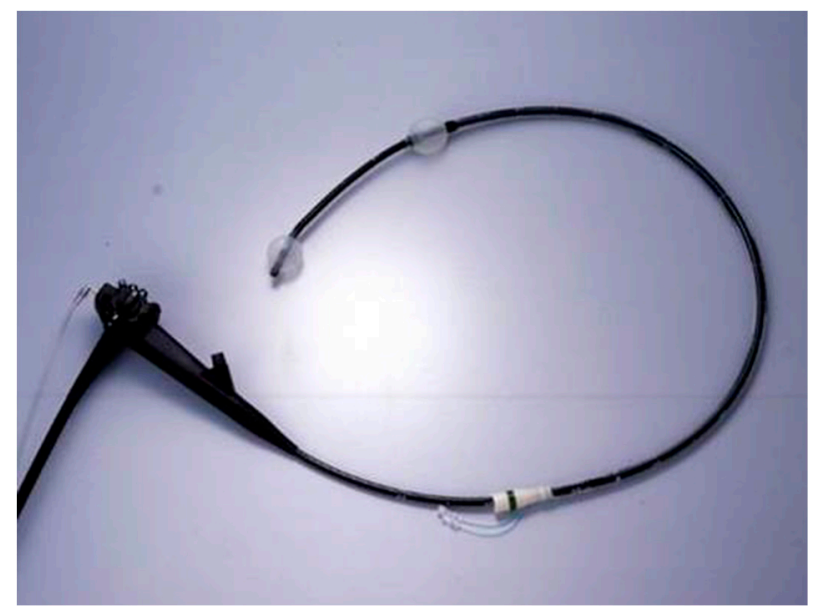

(a)

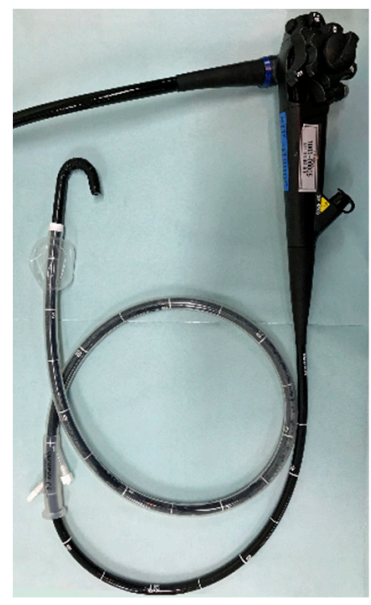

(b)

Figure 1. Balloon enteroscope: (a) double-balloon enteroscopy and (b) single-balloon enteroscopy.

Use of conventional SBE and DBE is limited by their long working length of $200 \mathrm{~cm}$. Therefore, only a few ERCP accessories are available. Recently, a short-type SBE (short SBE) and DBE (short DBE) with a working length of $152 \mathrm{~cm}$ (short SBE) and $155 \mathrm{~cm}$ (short DBE), and with a working channel diameter of $3.2 \mathrm{~mm}$ is available to increase accessories that can be used for BE-assisted ERCP. Moreover, the short SBE permits the function of passive bending and high-force transmission [10], and the short DBE permits the function of adaptive bending and advanced force transmission [11]. When using SBE, if the scope is at the intestinal tract wall when passing through a sharp flexure, then the passive bending section allows the scope to smoothly bend along the bend of the wall, making it possible to move forward. High-force transmission capabilities make it possible to perform torque operations efficiently and to provide better scope control. Therefore, it is also useful for bile duct cannulation and subsequent treatment procedures. In short, DBE, adaptive bending, and advanced force transmission provide a similar role to passive bending and high-force transmission. These features have contributed to overcoming the difficulties of scope insertion to the target site or biliary cannulation.

In general, ERCP-related procedures using BE are performed under conscious sedation, such as intravenous midazolam and pethidine. During scope insertion, patients are positioned in the prone position. However, for difficult cases, the position may be changed or abdominal pressure may be used. In case the BE forms a loop during insertion, the small intestine is fixed using the inflated balloon and shortened by withdrawing the BE. It is useful and safe for scope insertion to use carbon dioxide. In some difficult cases, such as long afferent limbs seen in Roux-en-Y reconstruction cases, it is difficult to proceed to the target site using short BE. Hence, a change to a conventional-type enteroscope (working length of $200 \mathrm{~cm}$ ) is required [12]. A transparent hood is useful not only for scope insertion but also for subsequent procedures, such as biliary cannulation [13]. Since postoperative adhesions tend to occur in patients with SAA, endoscopists could feel adhesions during scope insertion or shortening. It must be taken into consideration that there is an increased risk of perforation during scope insertion in patients with SAA than in anatomically normal cases. After achievement of scope insertion to the target site, biliary cannulation is performed using a catheter with a guidewire for cholangiography and deep cannulation. After biliary cannulation, endoscopic diagnosis/interventions, such as stone extraction, stent placement, and biopsy/cytology for diagnosis are performed.

Although endoscopic sphincterotomy (EST) is one of the common procedures in $\mathrm{ERCP}$, it can be particularly troublesome in patients with SAA (Billroth II gastrectomy or Roux-en-Y gastrectomy). It is considered to be difficult because the correct direction of the incision is sometimes uncertain due to the upside-down position in these patients. If the incision is made in the wrong direction, perforation could occur. One study from 
a tertiary referral endoscopy center evaluated 40 cases of the endoscopic papillary large balloon (over 10-mm) dilation (EPLBD) without EST for stone extraction in patients with Billroth II gastrectomy. Stones were successfully removed in all cases. Acute complications from EPLBD included mild pancreatitis in two patients (5.0\%) [14]. This result showed the usefulness and safety of EPLBD without EST. If an endoscopist feels difficult to perform EST in patients with Billroth II gastrectomy or Roux-en-Y gastrectomy, EPLBD without EST may be recommended.

\section{Single Balloon-Assisted ERCP}

Table 2 shows outcomes of SBE-assisted ERCP procedures in patients with SAA $[12,13,15-22]$. The latest systematic review and meta-analysis reported that the pooled data reaching the target site, biliary cannulation, and procedural success rates were $86.6 \%$, $90 \%$, and $75.8 \%$. Adverse events occurred in $6.6 \%$ of the procedures [23]. Fatal pancreatitis and intestinal perforation requiring surgical operation were included in the report. Although these were acceptable adverse event rates, we must be mindful that fatal adverse events can occur. It was also reported that bilateral stenting (partial stent-in-stent placement method) using self-expandable metallic stents for patients with hilar bile duct cancer was possible by use of short SBE [24].

Table 2. Outcomes of single balloon enteroscopy (SBE)-assisted endosopic retrograde cholangiopancreatography (ERCP) procedure in patients with surgically altered anatomy (SAA).

\begin{tabular}{ccccc}
\hline Authors & Year & $\begin{array}{c}\text { Reaching the Target } \\
\text { Site Success, } \%(\boldsymbol{n})\end{array}$ & $\begin{array}{c}\text { Biliary Cannulation } \\
\text { Success, } \%(\boldsymbol{n})\end{array}$ & $\begin{array}{c}\text { Procedural Success, } \\
\mathbf{\%}(\boldsymbol{n})\end{array}$ \\
\hline Wang et al. [15] & 2010 & $81.3(13 / 16)$ & $92.3(12 / 13)$ & $75.0(12 / 16)$ \\
\hline Shah et al. [16] & 2013 & $68.9(31 / 45)$ & $87.1(27 / 31)$ & $60.0(27 / 45)$ \\
\hline Lenze et al. [17] & 2014 & $73.1(19 / 26)$ & $78.9(15 / 19)$ & $57.7(15 / 26)$ \\
\hline Trindade et al. [13] & 2015 & $87.5(49 / 56)$ & $89.8(44 / 49)$ & $71.4(40 / 56)$ \\
\hline Kawamura et al. [18] & 2015 & $88.9(24 / 27)$ & $83.3(20 / 24)$ & $70.4(19 / 27)$ \\
\hline Yamauchi et al. [19] & 2015 & $90.5(76 / 84)$ & $89.5(68 / 76)$ & $77.4(65 / 84)$ \\
\hline Ishii et al. [20] & 2016 & $91.9(113 / 123)$ & $94.1(95 / 101)$ & $88.1(96 / 109)$ \\
\hline Yane et al. [21] & 2017 & $92.6(188 / 203)$ & $\mathrm{N} / \mathrm{A}$ & $81.8(166 / 203)$ \\
\hline Tanisaka et al. [12] & 2019 & $94.8(181 / 191)$ & $92.3(167 / 181)$ & $85.9(164 / 191)$ \\
\hline Sawas et al. [22] & 2020 & $86.0(37 / 43)$ & $83.8(31 / 37)$ & $69.8(30 / 43)$ \\
\hline
\end{tabular}

SBE, single-balloon enteroscopy. ERCP, endoscopic retrograde cholangiopancreatography. SAA, surgically altered anatomy. N/A, not available.

Selective biliary cannulation seems to be more difficult in patients with SAA than patients with normal anatomy. The reason is the following: the papilla appears inverted, the view of the papilla tends to be tangential, SBE is forward-viewing, and the elevator system is not equipped. There are several tips for biliary cannulation using SBE. As previously mentioned, the use of a transparent hood is effective for biliary cannulation [13]. Moreover, it was reported that suction of the papilla into the transparent cap facilitated biliary cannulation [25]. The retroflex position contributes to gaining a better view of the papilla in patients with Roux-en-Y gastrectomy. $[20,26]$. To achieve the retroflex position, the endoscope is advanced while using the upper angle at the inferior duodenal angle. The scope provides a J-turn form (Figure 2). Moreover, cannulation techniques, such as the double-guidewire method, insertion along the pancreatic duct (PD) stent [27], and use of the unique cannula equipped double-lumen [28] are useful. 


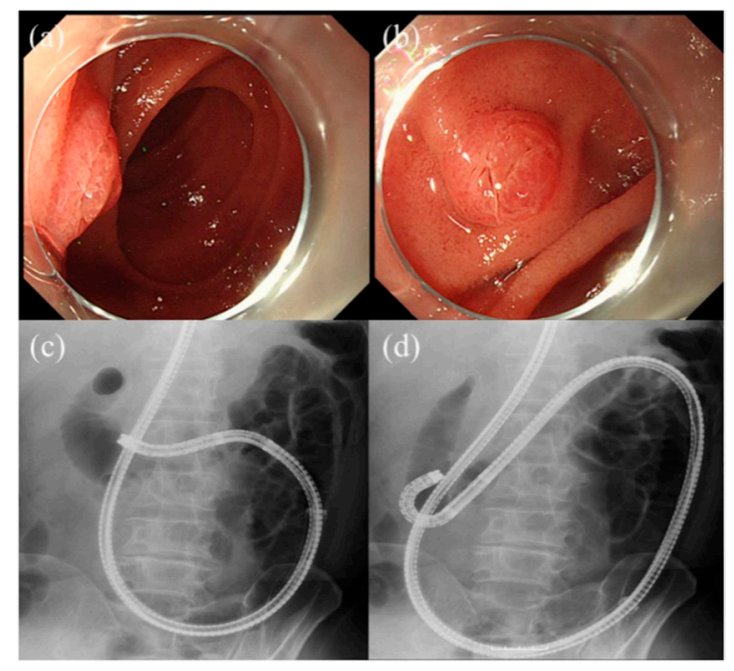

Figure 2. Retroflex position: $(\mathbf{a}, \mathbf{c})$. The papilla is positioned tangential, so it is difficult for biliary cannulation. (b,d) The endoscope is advanced while using the up angle at the inferior duodenal angle. As a result, it provides a better view of the papilla.

Some studies have reported factors affecting procedural results. One study reported that pancreatic indications, first ERCP attempt, and no transparent hood affected procedural failure [21]. Another study reported that malignant biliary obstruction, first ERCP attempt, and Roux-en-Y reconstruction affected procedural failure [12]. Figure 3 demonstrates endoscopic stone extraction using short SBE for patients with SAA.

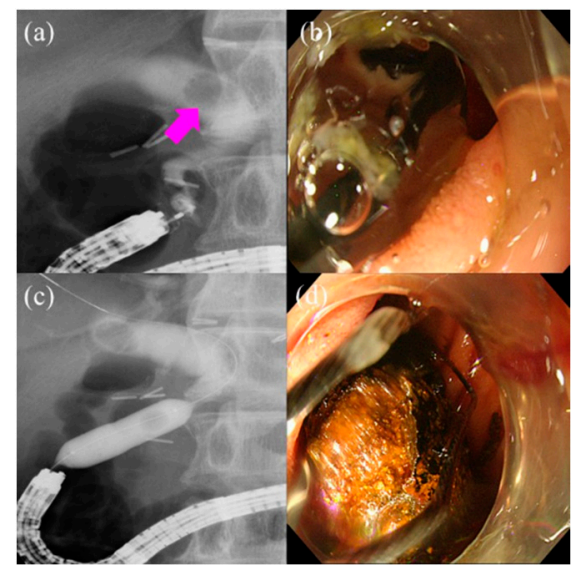

Figure 3. Endoscopic stone extraction using short single-balloon enteroscopy (short SBE) for patients with surgically altered anatomy (SAA): (a) Cholangiography showing a 15-mm biliary stone (pink arrow) in the distal bile duct. (b,c) Endoscopic papillary large balloon dilation was performed for stone extraction. The balloon was inflated up to 13-mm. (d) Stone extraction was completed without crushing.

\section{Double Balloon-Assisted ERCP}

Table 3 shows the outcomes of DBE-assisted ERCP procedures in patients with SAA [29-38]. The latest systematic review and meta-analysis reported that the pooled data reaching the target site, biliary cannulation, and procedural success rates were $90 \%, 94 \%$, and $93 \%$. Adverse events occurred in $4 \%$ [39]. One case of intestinal perforation requiring surgery was included in the report. A single-center large cohort study reported that Billroth II gastrectomy (B-II) and the native papilla were notable risk factors for complications [40]. In that report, especially cases of B-II with an extremely short afferent loop between the gastro-jejunal anastomosis and Treitz ligament, had a risk of perforation because B-II with 
an extremely short afferent loop tend to receive a strong force while proceeding a scope into the afferent loop. This kind of perforation could also occur in SBE.

Table 3. Outcomes of double balloon endoscopy (DBE)-assisted ERCP procedure in patients with surgically altered anatomy (SAA).

\begin{tabular}{ccccc}
\hline Authors & Year & $\begin{array}{c}\text { Reaching the Target } \\
\text { Site Success, } \%(n)\end{array}$ & $\begin{array}{c}\text { Biliary Cannulation } \\
\text { Success, } \%(n)\end{array}$ & $\begin{array}{c}\text { Procedural Success, } \\
\text { \% }(\boldsymbol{n})\end{array}$ \\
\hline Aabakken et al. [29] & 2007 & $94.4(17 / 18)$ & $88.2(15 / 17)$ & $83.3(15 / 18)$ \\
\hline Emmett et al. [30] & 2007 & $85.0(17 / 20)$ & $94.1(16 / 17)$ & $80.0(16 / 20)$ \\
\hline Shimatani et al. [31] & 2009 & $97.1(100 / 103)$ & $98.0(98 / 100)$ & $95.1(98 / 103)$ \\
\hline Cho et al. [32] & 2011 & $86.2(25 / 29)$ & $96.0(24 / 25)$ & $82.8(24 / 29)$ \\
\hline Tsutsumi et al. [33] & 2015 & $98.6(71 / 72)$ & $100(71 / 71)$ & $98.6(71 / 72)$ \\
\hline Cheng et al. [34] & 2015 & $94.8(73 / 77)$ & $94.5(69 / 73)$ & $87.0(67 / 77)$ \\
\hline Shimatani et al. [35] & 2016 & $97.7(304 / 311)$ & $96.4(293 / 304)$ & $92.3(287 / 311)$ \\
\hline Liu et al. [36] & 2017 & $75.6(65 / 86)$ & $92.3(60 / 65)$ & $69.8(60 / 86)$ \\
\hline Kashani et al. [37] & 2018 & $93.8(121 / 129)$ & N/A & $88.4(114 / 129)$ \\
\hline Uchida et al. [38] & 2020 & $94.3(759 / 805)$ & N/A & $90.7(730 / 805)$ \\
\hline
\end{tabular}

DBE, double-balloon enteroscopy. ERCP, endoscopic retrograde cholangiopancreatography. SAA, surgically altered anatomy. N/A, not available.

There are several technical tips for DBE. As previously mentioned, the retroflex position is also useful for biliary cannulation using DBE. Since the working channel port shows up in a 5:30 o'clock direction on the endoscopic screen, positioning and fixing the papilla in a $6 \mathrm{o}^{\prime}$ clock direction is effective to perform endoscopic sphincterotomy safely [41]. This position provides the oral protrusion and the hooding fold, which are landmarks of the direction of bile duct in performing endoscopic sphincterotomy. Furthermore, it enables confirmation whether common bile duct stones are present or not between the balloon and common bile duct during endoscopic papillary large balloon dilation [42].

Factors affecting procedural results using DBE have also been reported. One study noted that patients with surgery during childhood, biliary atresia, and second operation post-transplant were factors affecting procedure results in patients with Roux-en-Y reconstruction [36]. Another study reported that Roux-en-Y reconstruction and the first-time procedure affected the outcomes and adverse events [38]. In the report, a physician in training did not significantly affect the outcomes.

\section{Other Device-Assisted ERCP}

There are several reports of ERCP using other devices. Motorized spiral enteroscopy (PSF-1, Olympus Medical Systems, Tokyo, Japan) with a working length of $168 \mathrm{~cm}$, and with a working channel diameter of $3.2 \mathrm{~mm}$ is available from 2015. The drive motor located in the endoscope handle is activated by foot pedals and controls the direction and speed of rotation of a coupler located in the middle of the endoscope's insertion tube. The single-use spiral assembly is composed of corrugated tubing with an atraumatic plastic spiral bonded to its exterior. It relies on rotation of the spiral component to "pleat" or "un-pleat" the bowel either on or off the insertion tube as the spiral thread rotates in a clockwise or counterclockwise direction, respectively [43-45]. It has been evaluated in prospective clinical trials and shown to be safe and effective for deep enteroscopy [45]. Moreover, in view of ERCP, it allows the uses of standard ERCP-accessories in the same way as short SBE and DBE. Actually, there is one report published regarding motorized spiral enteroscopy-assisted ERCP in a patient with SAA, showing successful and rapid enteroscopic access, cannulation, and balloon dilation therapy [46]. Although further studies are needed, it could be the upcoming ERCP technology in pa-tients with SAA. 
Moreover, laparoscopy-assisted ERCP (LA-ERCP) is accomplished by placing a trocar in the remnant stomach under laparoscopic guidance followed by insertion of the conventional duodenoscope through the trocar to reach the papilla. ERCP is then carried out in a standard method. The advantage of LA-ERCP is that the duodenoscope, which is used for ERCP when normal anatomy is available. It was reported that LA-ERCP achieved high success rates $[47,48]$. A multicenter study reported that the procedural success, and adverse events rates were 98\%, and 18\% (laparoscopy related, 10\%, ERCP related, 7\%, both, $1 \%$ ) [49]. Although there is a high success rate, the overall adverse event rate was high due to the added laparoscopy-related events.

\section{Interventional EUS}

Despite the high effectiveness reported for BE-assisted ERCP in patients with SAA, it has several challenges for successful completion of procedures. Alternative treatment modalities are needed for some cases. Percutaneous transhepatic biliary drainage (PTBD) has been traditionally performed in these patients despite PTBD being associated with a higher adverse event rate than ERCP [50]. PTBD is conventionally performed using the following three-step approach: (1) external drainage with confirmation of clinical improvement, (2) stent deployment with maintenance of the external drainage tube, and (3) external drainage tube removal after the confirmation of proper drainage through the stent. Although PTBD is one of the alternatives, it may be impractical for urgent cases due to the requirement of serial dilation and track maturation [51]. Moreover, external drainage tube trouble could be caused. However, PTBD is possible to perform stone extraction effectively and safely, so we can choose PTBD as the alternatives for cases of difficult stone extraction using BE.

Recently, interventional EUS has been in the spotlight as an alternative therapy for patients with difficult ERCP, such as scope insertion and biliary cannulation. Interventional EUS may be a first-line treatment in some cases, such as malignant cases with cancer invasion of the small intestines or papilla [12].

There are several drainage methods for interventional EUS [52]. The first method is the EUS-guided hepaticogastrostomy (EUS-HGS). Generally, the left intrahepatic bile duct (B 2 or 3) is punctured to make the drainage route. After cholangiography and guidewire insertion, the fistula is dilated using a dilation device followed by the placement of a biliary stent [53]. If the stomach has been resected, such as in Roux-en-Y gastrectomy cases, a puncture is performed from the jejunal limb. The second method is EUS-guided antegrade stenting (EUS-AG). After puncture of the left intrahepatic bile duct, a guidewire is directed to the papilla or hepaticojejunal anastomosis, and the biliary stent is placed via an antegrade route [54]. Moreover, the EUS-guided rendezvous technique (EUS-RV) is also a useful alternative procedure [55]. In cases of difficult biliary cannulation using a BE, after the left intrahepatic bile duct (B2 or B3) is punctured, the guidewire is directed beyond the papilla or hepaticojejunal anastomosis. As a result, the guidewire is positioned into the duodenum or jejunum. Afterward, a scope exchange from the echoendoscope to BE is carried out. The guidewire is grasped using a forceps device and pulled into the working channel. Finally, biliary cannulation through the papilla or anastomotic site is successful.

Table 4 shows outcomes of EUS-guided biliary drainage (EUS-BD) [56-64]. The latest systematic review and meta-analysis reported that the pooled technical success rates and clinical success rates were $91.5 \%$ and $87 \%$, respectively. Adverse events occurred in $17.9 \%$. The main adverse events were bile leakage $(4.1 \%)$, stent migration $(3.9 \%)$, and infections (3.8\%) [65]. Although there were high success rates using interventional EUS, adverse events were higher than BE-assisted ERCP. Therefore, EUS-BD should be performed carefully and endoscopists should take into consideration that severe adverse events could develop. Figure 4 provides the successful EUS-HGS in a patient with SAA. Although SBE-assisted ERCP was initially performed, it failed due to cancer invasion of the small intestine. 
Table 4. Outcomes of endoscopic ultrasound (EUS)-guided biliary drainage.

\begin{tabular}{ccccc}
\hline Authors & Year & $\begin{array}{c}\text { Technical Success, } \\
\mathbf{\%}(\boldsymbol{n})\end{array}$ & $\begin{array}{c}\text { Clinical Success, } \\
\mathbf{\%}(\boldsymbol{n})\end{array}$ & $\begin{array}{c}\text { Adverse Events, } \\
\mathbf{\%}(\boldsymbol{n})\end{array}$ \\
\hline Shah et al. [56] & 2011 & $70.5(62 / 88)$ & $70.5(62 / 88)$ & $6.8(6 / 88)$ \\
\hline Khashab et al. [57] & 2013 & $94.3(33 / 35)$ & $91.4(32 / 35)$ & $11.4(4 / 35)$ \\
\hline Park et al. [58] & 2013 & $91.1(41 / 45)$ & $86.7(39 / 45)$ & $8.9(4 / 45)$ \\
\hline Kawakubo et al. [59] & 2014 & $95.3(61 / 64)$ & $\mathrm{N} / \mathrm{A}$ & $18.8(12 / 64)$ \\
\hline Gupta et al. [60] & 2014 & $88.5(207 / 234)$ & $\mathrm{N} / \mathrm{A}$ & $34.6(81 / 234)$ \\
\hline Dhir et al. [61] & 2015 & $93.3(97 / 104)$ & $89.4(93 / 104)$ & $8.7(9 / 104)$ \\
\hline Kahaleh et al. [62] & 2016 & $91.4(32 / 35)$ & $88.6(31 / 35)$ & $25.7(9 / 35)$ \\
\hline Tsuchiya et al. [63] & 2018 & $100(19 / 19)$ & $94.7(18 / 19)$ & $36.8(7 / 19)$ \\
\hline Minaga et al. [64] & 2019 & $85.2(46 / 54)$ & $85.2(46 / 54)$ & $18.5(10 / 54)$ \\
\hline
\end{tabular}

EUS, endoscopic ultrasound. N/A, not available.

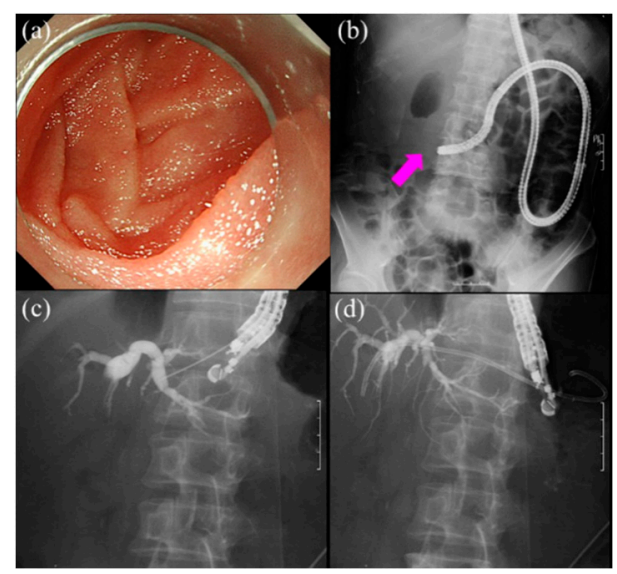

Figure 4. Endoscopic ultrasound-guided hepaticogastrostomy for patients with surgically altered anatomy (SAA) showing a failed case of single-balloon enteroscopy-assisted (SBE) endoscopic retrograde cholangiopancreatography (ERCP). (a) It was impossible to reach the papilla due to cancer invasion of the duodenum. (b) Fluoroscopic image showing duodenal obstruction due to cancer invasion (pink arrow). (c) Endoscopic ultrasound-guided hepaticogastrostomy is performed. First, B 3 is punctured using a 19-gauge needle. After puncture, we performed cholangiography to confirm the position of the guidewire. (d) Finally, a biliary stent was placed.

\section{Comparison between BE-Assisted ERCP and Interventional EUS}

Some papers have conducted a comparison between BE-assisted ERCP and EUS-BD in patients with SAA. A multicenter retrospective study reported that clinical success was $88 \%$ in the EUS-BD group. It was $59.1 \%$ in the BE-assisted ERCP group (odds ratio [OR] 2.83, $p=0.03$ ). The EUS-BD group completed the procedure in a shorter amount of time than the BE-assisted ERCP group (55 min vs. 95 min, $p<0.0001$ ). However, adverse events occurred more often in the EUS-BD group ( $20 \%$ vs. $4 \%, p=0.01$ ) [66]. An international multicenter study compared EUS-BD and BE-assisted ERCP in patients with Roux-en-Y gastric bypass and showed that the technical success rate of EUS-BD was superior to BE-assisted ERCP $(100 \%$ vs. $60 \%)$. Adverse events occurred comparably [67]. These comparison studies had lower success rates than studies in Tables 2 and 3. These comparison studies' population were almost all R-Y reconstruction. Studies in Tables 2 and 3 included Billroth II gastrectomy and pancreaticoduodenectomy, which are considered to be easier than R-Y. Therefore, these success rates for BE would be lower than Tables 2 and 3.

Although interventional EUS provided a higher success rate and shorter procedure time, adverse events tended to be high. A fatal complication, such as aberrant stent displacement into the abdominal cavity, has been reported [68]. Dedicated devices used by EUS-BD are warranted for safety. Hence, the choice between BE-assisted ERCP and 
interventional EUS depends on the postoperative reconstruction, patient's condition, or the expertise of the endoscopist.

\section{Conclusions}

We discussed recent advances in interventional ERCP and EUS for patients with SAA. Both BE-assisted ERCP and interventional EUS have advantages and disadvantages. The choice of procedure should be individualized to the patient's condition or the expertise of the endoscopist. We propose the following interventional strategy for patients with SAA (Figure 5). First, if tumor invasion to the small intestine can be adequately predicted prior to the procedure by cross-sectional imaging, such as computed tomography, the most appropriate technique for the case, such as PTBD or EUS-BD, can be selected as alternative interventions. During the procedure, if the target site (papilla or hepaticojejunal anastomosis) cannot be reached using a BE, laparoscopy-assisted ERCP, PTBD, or EUS-BD will be required to complete the treatment procedure. In case of failed biliary cannulation or an intended procedure, reattempting BE-assisted ERCP, PTBD, or EUS-BD should be selected according to the previous treatment.

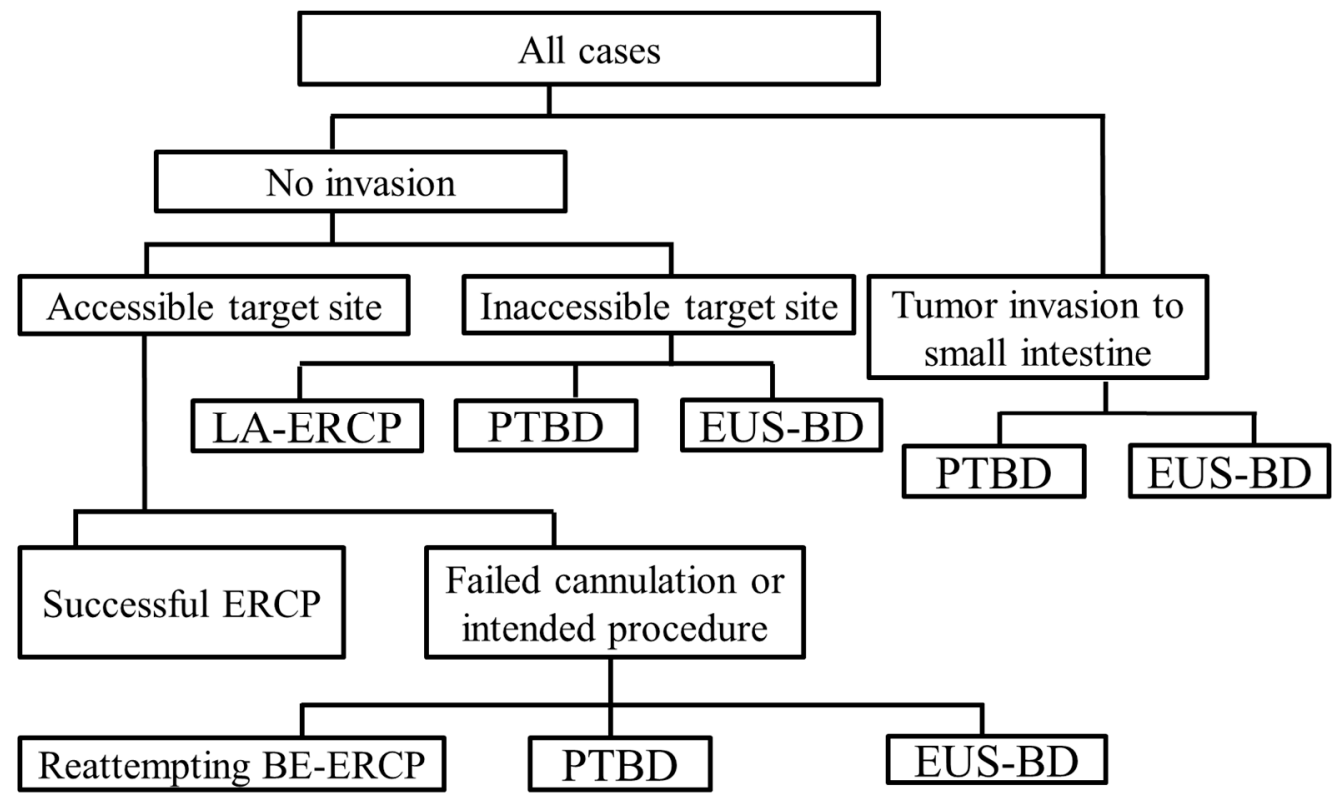

Figure 5. Flowchart of our proposed interventional strategy for patients with surgically altered anatomy (SAA). ERCP, endoscopic retrograde cholangiopancreatography. EUS-BD, endoscopic ultrasound-guided biliary drainage. PTBD, percutaneous transhepatic biliary drainage. LA-ERCP, laparoscopy-assisted ERCP. BE-ERCP, balloon enteroscope-assisted ERCP.

Further improvement of both BE-assisted ERCP and interventional EUS are needed to perform effective and safe procedures for patients with SAA.

Author Contributions: The paper was authored by Y.T., who designed and drafted the article. M.M., A.F., T.O., M.S., H.K., Y.S., K.M., T.T., Y.M., and S.R. provided a critical revision of the article for important intellectual content. Y.T. finally approved the article for submission. The final version of the manuscript was approved by all authors. All authors have read and agreed to the published version of the manuscript.

Funding: This research received no external funding.

Institutional Review Board Statement: Not applicable.

Informed Consent Statement: Not applicable.

Data Availability Statement: Data sharing not applicable.

Conflicts of Interest: The authors declare no conflict of interest. 


\section{References}

1. Freeman, M.L.; Guda, N.M. ERCP cannulation: A review of reported techniques. Gastrointest. Endosc. 2005, 61, 112-125. [CrossRef]

2. Suissa, A.; Yassin, K.; Lavy, A.; Lachter, J.; Chermech, I.; Karban, A.; Tamir, A.; Eliakim, R. Outcome and early complications of ERCP: A prospective single center study. Hepatogastroenterology 2005, 52, 352-355. [PubMed]

3. Elton, E.; Hanson, B.L.; Qaseem, T.; Howell, D.A. Diagnostic and therapeutic ERCP using an enteroscope and a pediatric colonoscope in long-limb surgical bypass patients. Gastrointest. Endosc. 1998, 47, 62-67. [CrossRef]

4. Wright, B.E.; Cass, O.W.; Freeman, M.L. ERCP in patients with long-limb Roux-en-Y gastrojejunostomy and intact papilla. Gastrointest. Endosc. 2002, 56, 225-232. [CrossRef]

5. Teplick, S.K.; Flick, P.; Brandon, J.C. Transhepatic cholangiography in patients with suspected biliary disease and nondilated intrahepatic bile ducts. Gastrointest. Radiol. 1991, 16, 193-197. [CrossRef]

6. Ko, G.Y.; Sung, K.B.; Yoon, H.K.; Kim, K.R.; Gwon, D.I.; Lee, S.G. Percutaneous transhepatic treatment of hepaticojejunal anastomotic biliary strictures after living donor liver transplantation. Liver Transpl. 2008, 14, 1323-1332. [CrossRef] [PubMed]

7. Bove, V.; Tringali, A.; Familiari, P.; Gigante, G.; Boškoski, I.; Perri, V.; Mutignani, M.; Costamagna, G. ERCP in patients with prior Billroth II gastrectomy: Report of 30 years' experience. Endoscopy 2015, 47, 611-616. [CrossRef]

8. Park, T.Y.; Bang, C.S.; Choi, S.H.; Yang, Y.J.; Shin, S.P.; Suk, K.T.; Baik, G.H.; Kim, D.J.; Yoon, J.H. Forward-viewing endoscope for ERCP in patients with Billroth II gastrectomy: A systematic review and meta-analysis. Surg. Endosc. 2018, 32, 4598-4613. [CrossRef]

9. Yamamoto, H.; Sekine, Y.; Sato, Y.; Higashizawa, T.; Miyata, T.; Iino, S.; Ido, K.; Sugano, K. Total enteroscopy with a nonsurgical steerable double-balloon method. Gastrointest. Endosc. 2001, 53, 216-220. [CrossRef]

10. Tanisaka, Y.; Ryozawa, S.; Mizuide, M.; Kobayashi, M.; Fujita, A.; Minami, K.; Kobatake, T.; Omiya, K.; Iwano, H.; Araki, R. Usefulness of the "newly designed" short-type single-balloon enteroscope for ERCP in patients with Roux-en-Y gastrectomy: A pilot study. Endosc. Int. Open 2018, 6, E1417-E1422. [CrossRef]

11. Shimatani, M.; Tokuhara, M.; Kato, K.; Miyamoto, S.; Masuda, M.; Sakao, M.; Fukata, N.; Miyoshi, H.; Ikeura, T.; Takaoka, M.; et al. Utility of newly developed short-type double-balloon endoscopy for endoscopic retrograde cholangiography in postoperative patients. J. Gastroenterol. Hepatol. 2017, 32, 1348-1354. [CrossRef]

12. Tanisaka, Y.; Ryozawa, S.; Mizuide, M.; Harada, M.; Fujita, A.; Ogawa, T.; Nonaka, K.; Tashima, T.; Araki, R. Analysis of the factors involved in procedural failure: Endoscopic retrograde cholangiopancreatography using a short-type single-balloon enteroscope for patients with surgically altered gastrointestinal anatomy. Dig. Endosc. 2019, 31, 682-689. [CrossRef]

13. Trindade, A.J.; Mella, J.M.; Slattery, E.; Cohen, J.; Dickstein, J.; Garud, S.S.; Chuttani, R.; Pleskow, D.K.; Sawhney, M.S.; Berzin, T.M. Use of a cap in single-balloon enteroscopy-assisted endoscopic retrograde cholangiography. Endoscopy 2015, 47, 453-456. [CrossRef]

14. Jang, H.W.; Lee, K.J.; Jung, M.J.; Jung, J.W.; Park, J.Y.; Park, S.W.; Song, S.Y.; Chung, J.B.; Bang, S. Endoscopic papillary large balloon dilatation alone is safe and effective for the treatment of difficult choledocholithiasis in cases of Billroth II gastrectomy: A single center experience. Dig. Dis. Sci. 2013, 58, 1737-1743. [CrossRef]

15. Wang, A.Y.; Sauer, B.G.; Behm, B.W.; Ramanath, M.; Cox, D.G.; Ellen, K.L.; Shami, V.M.; Kahaleh, M. Single-balloon enteroscopy effectively enables diagnostic and therapeutic retrograde cholangiography in patients with surgically altered anatomy. Gastrointest. Endosc. 2010, 71, 641-649. [CrossRef]

16. Shah, R.J.; Smolkin, M.; Yen, R.; Ross, A.; Kozarek, R.A.; Howell, D.A.; Bakis, G.; Jonnalagadda, S.S.; Al-Lehibi, A.A.; Hardy, A.; et al. A multicenter, U.S. experience of single-balloon, double-balloon, and rotational overtube-assisted enteroscopy ERCP in patients with surgically altered pancreaticobiliary anatomy (with video). Gastrointest. Endosc. 2013, 77, 593-600. [CrossRef] [PubMed]

17. Lenze, F.; Meister, T.; Matern, P.; Heinzow, H.S.; Domschke, W.; Ullerich, H. Single-balloon enteroscopy-assisted endoscopic retrograde cholangiopancreaticography in patients with surgically altered anatomy: Higher failure rate in malignant biliary obstruction-A prospective single center cohort analysis. Scand. J. Gastroenterol. 2014, 49, 766-771. [CrossRef] [PubMed]

18. Kawamura, T.; Uno, K.; Suzuki, A.; Mandai, K.; Nakase, K.; Tanaka, K.; Yasuda, K. Clinical usefulness of a short-type, prototype single-balloon enteroscope for endoscopic retrograde cholangiopancreatography in patients with altered gastrointestinal anatomy: Preliminary experiences. Dig. Endosc. 2015, 27, 82-86. [CrossRef] [PubMed]

19. Yamauchi, H.; Kida, M.; Okuwaki, K.; Miyazawa, S.; Iwai, T.; Tokunaga, S.; Takezawa, M.; Imaizumi, H.; Koizumi, W. Passivebending, short-type single-balloon enteroscope for endoscopic retrograde cholangiopancreatography in Roux-en-Y anastomosis patients. World J. Gastroenterol. 2015, 21, 1546-1553. [CrossRef] [PubMed]

20. Ishii, K.; Itoi, T.; Tonozuka, R.; Itokawa, F.; Sofuni, A.; Tsuchiya, T.; Tsuji, S.; Ikeuchi, N.; Kamada, K.; Umeda, J.; et al. Balloon enteroscopy-assisted ERCP in patients with Roux-en-Y gastrectomy and intact papillae (with videos). Gastrointest. Endosc. 2016, 83, 377-386. [CrossRef]

21. Yane, K.; Katanuma, A.; Maguchi, H.; Takahashi, K.; Kin, T.; Ikarashi, S.; Sano, I.; Yamazaki, H.; Kitagawa, K.; Yokoyama, K.; et al. Short-type single-balloon enteroscope-assisted ERCP in postsurgical altered anatomy: Potential factors affecting procedural failure. Endoscopy 2017, 49, 69-74. [CrossRef] [PubMed] 
22. Sawas, T.; Storm, A.C.; Bazerbachi, F.; Fleming, C.J.; Vargas, E.J.; Chandrasekhara, V.; Andrews, J.C.; Levy, M.J.; Martin, J.A.; Petersen, B.T.; et al. An innovative technique using a percutaneously placed guidewire allows for higher success rate for ERCP compared to balloon enteroscopy assistance in Roux-en-Y gastric bypass anatomy. Surg. Endosc. 2020, 34, 806-813. [CrossRef]

23. Tanisaka, Y.; Ryozawa, S.; Mizuide, M.; Araki, R.; Fujita, A.; Ogawa, T.; Tashima, T.; Noguchi, T.; Suzuki, M.; Katsuda, H. Status of single-balloon enteroscopy-assisted endoscopic retrograde cholangiopancreatography in patients with surgically altered anatomy: Systematic review and meta-analysis on biliary interventions. Dig. Endosc. 2020. [CrossRef] [PubMed]

24. Tanisaka, Y.; Ryozawa, S.; Mizuide, M.; Fujita, A.; Ogawa, T.; Tashima, T.; Noguchi, T.; Suzuki, M.; Katsuda, H.; Araki, R. Usefulness of self-expandable metal stents for malignant biliary obstruction using a short-type single-balloon enteroscope in patients with surgically altered anatomy. J. Hepatobiliary Pancreat. Sci. 2021, 28, 272-279. [CrossRef] [PubMed]

25. Zimmer, V. Mission (nearly) impossible: ERCP using an oblique cap with suction cannulation in a diffusely strictured duodenal stump after Billroth II with Braun enteroenterostomy. Endoscopy 2020, 52, E63-E65. [CrossRef]

26. Tanisaka, Y.; Ryozawa, S.; Mizuide, M.; Fujita, A.; Ogawa, T.; Harada, M.; Noguchi, T.; Suzuki, M.; Araki, R. Biliary Cannulation in Patients with Roux-en-Y Gastrectomy: An Analysis of the Factors Associated with Successful Cannulation. Intern. Med. 2020, 59, 1687-1693. [CrossRef]

27. Tanisaka, Y.; Ryozawa, S.; Mizuide, M.; Fujita, A.; Harada, M.; Ogawa, T. Novel technique using pancreatic duct stent facilitates difficult biliary cannulation in patients with Roux-en-Y anatomy (with video). JGH Open 2019, 4, 296-298. [CrossRef]

28. Takenaka, M.; Minaga, K.; Kamata, K.; Yamao, K.; Yoshikawa, T.; Ishikawa, R.; Okamoto, A.; Yamazaki, T.; Nakai, A.; Omoto, S.; et al. Efficacy of a modified double-guidewire technique using an uneven double lumen cannula (uneven method) in patients with surgically altered gastrointestinal anatomy (with video). Surg. Endosc. 2020, 34, 1432-1441. [CrossRef]

29. Aabakken, L.; Bretthauer, M.; Line, P.D. Double-balloon enteroscopy for endoscopic retrograde cholangiography in patients with a Roux-en-Y anastomosis. Endoscopy 2007, 39, 1068-1071. [CrossRef]

30. Emmett, D.S.; Mallat, D.B. Double-balloon ERCP in patients who have undergone Roux-en-Y surgery: A case series. Gastrointest. Endosc. 2007, 66, 1038-1041. [CrossRef]

31. Shimatani, M.; Matsushita, M.; Takaoka, M.; Koyabu, M.; Ikeura, T.; Kato, K.; Fukui, T.; Uchida, K.; Okazaki, K. Effective “short” double-balloon enteroscope for diagnostic and therapeutic ERCP in patients with altered gastrointestinal anatomy: A large case series. Endoscopy 2009, 41, 849-854. [CrossRef]

32. Cho, S.; Kamalaporn, P.; Kandel, G.; Kortan, P.; Marcon, N.; May, G. 'Short' double-balloon enteroscope endoscopic retrograde cholangiopancreatography in patients with a surgically altered upper gastrointestinal tract. Can. J. Gastroenterol. 2011, 25, 615-619. [CrossRef]

33. Tsutsumi, K.; Kato, H.; Muro, S.; Yamamoto, N.; Noma, Y.; Horiguchi, S.; Harada, R.; Okada, H.; Yamamoto, K. ERCP using a short double-balloon enteroscope in patients with prior pancreatoduodenectomy: Higher maneuverability supplied by the efferent-limb route. Surg. Endosc. 2015, 29, 1944-1951. [CrossRef] [PubMed]

34. Cheng, C.L.; Liu, N.J.; Tang, J.H.; Yu, M.C.; Tsui, Y.N.; Hsu, F.Y.; Lee, C.S.; Lin, C.H. Double-balloon enteroscopy for ERCP in patients with Billroth II anatomy: Results of a large series of papillary large-balloon dilation for biliary stone removal. Endosc. Int. Open 2015, 3, E216-E222. [CrossRef]

35. Shimatani, M.; Hatanaka, H.; Kogure, H.; Tsutsumi, K.; Kawashima, H.; Hanada, K.; Matsuda, T.; Fujita, T.; Takaoka, M.; Yano, T.; et al. Diagnostic and Therapeutic Endoscopic Retrograde Cholangiography Using a Short-Type Double-Balloon Endoscope in Patients With Altered Gastrointestinal Anatomy: A Multicenter Prospective Study in Japan. Am. J. Gastroenterol. 2016, 111, 1750-1758. [CrossRef]

36. Liu, K.; Joshi, V.; Saxena, P.; Kaffes, A.J. Predictors of success for double balloon-assisted endoscopic retrograde cholangiopancreatography in patients with Roux-en-Y anastomosis. Dig. Endosc. 2017, 29, 190-197. [CrossRef] [PubMed]

37. Kashani, A.; Abboud, G.; Lo, S.K.; Jamil, L.H. Double balloon enteroscopy-assisted endoscopic retrograde cholangiopancreatography in Roux-en-Y gastric bypass anatomy: Expert vs. novice experience. Endosc. Int. Open 2018, 6, E885-E891. [CrossRef] [PubMed]

38. Uchida, D.; Tsutsumi, K.; Kato, H.; Matsumi, A.; Saragai, Y.; Tomoda, T.; Matsumoto, K.; Horiguchi, S.; Okada, H. Potential Factors Affecting Results of Short-Type Double-Balloon Endoscope-Assisted Endoscopic Retrograde Cholangiopancreatography. Dig. Dis. Sci. 2020, 65, 1460-1470. [CrossRef] [PubMed]

39. Anvari, S.; Lee, Y.; Patro, N.; Soon, M.S.; Doumouras, A.G.; Hong, D. Double-balloon enteroscopy for diagnostic and therapeutic ERCP in patients with surgically altered gastrointestinal anatomy: A systematic review and meta-analysis. Surg. Endosc. 2021, 35, 18-36. [CrossRef]

40. Tokuhara, M.; Shimatani, M.; Mitsuyama, T.; Masuda, M.; Ito, T.; Miyamoto, S.; Fukata, N.; Miyoshi, H.; Ikeura, T.; Takaoka, M.; et al. Evaluation of complications after endoscopic retrograde cholangiopancreatography using a short type double balloon endoscope in patients with altered gastrointestinal anatomy: A single-center retrospective study of 1,576 procedures. $J$. Gastroenterol. Hepatol. 2020, 35, 1387-1396. [CrossRef]

41. Shimatani, M.; Takaoka, M.; Okazaki, K. Tips for double balloon enteroscopy in patients with Roux-en-Y reconstruction and modified child surgery. J. Hepatobiliary Pancreat. Sci. 2014, 21, E22-E28. [CrossRef] [PubMed]

42. Shimatani, M.; Takaoka, M.; Mitsuyama, T.; Miyoshi, H.; Ikeura, T.; Okazaki, K. Complication of endoscopic papillary largeballoon dilation using double-balloon endoscopy for biliary stones in a postoperative patient. Endoscopy 2014, 46 (Suppl. 1), E390. [CrossRef] 
43. Beyna, T.; Schneider, M.; Pullmann, D.; Gerges, C.; Kandler, J.; Neuhaus, H. Motorized spiral colonoscopy: A first single-center feasibility trial. Endoscopy 2018, 50, 518-523. [CrossRef] [PubMed]

44. Neuhaus, H.; Beyna, T.; Schneider, M.; Devière, J. Novel motorized spiral enteroscopy: First clinical case. VideoGIE 2016, 1, 32-33. [CrossRef] [PubMed]

45. Beyna, T.; Arvanitakis, M.; Schneider, M.; Gerges, C.; Böing, D.; Devière, J.; Neuhaus, H. Motorised spiral enteroscopy: First prospective clinical feasibility study. Gut 2021, 70, 261-267.

46. Beyna, T.; Schneider, M.; Höllerich, J.; Neuhaus, H. Motorized spiral enteroscopy-assisted ERCP after Roux-en-Y reconstructive surgery and bilioenteric anastomosis: First clinical case. VideoGIE 2020, 5, 311-313. [CrossRef] [PubMed]

47. Lopes, T.L.; Clements, R.H.; Wilcox, C.M. Laparoscopy-assisted ERCP: Experience of a high-volume bariatric surgery center (with video). Gastrointest. Endosc. 2009, 70, 1254-1259. [CrossRef] [PubMed]

48. Saleem, A.; Levy, M.J.; Petersen, B.T.; Que, F.G.; Baron, T.H. Laparoscopic assisted ERCP in Roux-en-Y gastric bypass (RYGB) surgery patients. J. Gastrointest. Surg. 2012, 16, 203-208. [CrossRef]

49. Abbas, A.M.; Strong, A.T.; Diehl, D.L.; Brauer, B.C.; Lee, I.H.; Burbridge, R.; Zivny, J.; Higa, J.T.; Falcão, M.; El Hajj, I.I.; et al. Multicenter evaluation of the clinical utility of laparoscopy-assisted ERCP in patients with Roux-en-Y gastric bypass. Gastrointest. Endosc. 2018, 87, 1031-1039. [CrossRef]

50. Inamdar, S.; Slattery, E.; Bhalla, R.; Sejpal, D.V.; Trindade, A.J. Comparison of adverse events for endoscopic vs percutaneous biliary drainage in the treatment of malignant biliary tract obstruction in an inpatient national cohort. JAMA Oncol. 2016, 2, 112-117. [CrossRef]

51. Choi, E.K.; Chiorean, M.V.; Coté, G.A.; El Hajj, I.I.; Ballard, D.; Fogel, E.L.; Watkins, J.L.; McHenry, L.; Sherman, S.; Lehman, G.A. ERCP via gastrostomy vs. double balloon enteroscopy in patients with prior bariatric Roux-en-Y gastric bypass surgery. Surg. Endosc. 2013, 27, 2894-2899. [CrossRef]

52. Katanuma, A.; Hayashi, T.; Kin, T.; Toyonaga, H.; Honta, S.; Chikugo, K.; Ueki, H.; Ishii, T.; Takahashi, K. Interventional endoscopic ultrasonography in patients with surgically altered anatomy: Techniques and literature review. Dig. Endosc. 2020, 32, 263-274. [CrossRef]

53. Nakai, Y.; Sato, T.; Hakuta, R.; Ishigaki, K.; Saito, K.; Saito, T.; Takahara, N.; Hamada, T.; Mizuno, S.; Kogure, H.; et al. Longterm outcomes of a long, partially covered metal stent for EUS-guided hepaticogastrostomy in patients with malignant biliary obstruction (with video). Gastrointest. Endosc. 2020, 92, 623-631. [CrossRef]

54. Iwashita, T.; Yasuda, I.; Doi, S.; Uemura, S.; Mabuchi, M.; Okuno, M.; Mukai, T.; Itoi, T.; Moriwaki, H. Endoscopic ultrasoundguided antegrade treatments for biliary disorders in patients with surgically altered anatomy. Dig. Dis. Sci. 2013, 58, 2417-2422. [CrossRef]

55. Matsubara, S.; Nakagawa, K.; Suda, K.; Otsuka, T.; Isayama, H.; Nakai, Y.; Oka, M.; Nagoshi, S. A Proposed Algorithm for Endoscopic Ultrasound-Guided Rendezvous Technique in Failed Biliary Cannulation. J. Clin. Med. 2020, 9, 3879. [CrossRef]

56. Shah, J.N.; Marson, F.; Weilert, F.; Bhat, Y.M.; Nguyen-Tang, T.; Shaw, R.E.; Binmoeller, K.F. Single-operator, single-session EUS-guided anterograde cholangiopancreatography in failed ERCP or inaccessible papilla. Gastrointest. Endosc. 2012, 75, 56-64. [CrossRef] [PubMed]

57. Khashab, M.A.; Valeshabad, A.K.; Modayil, R.; Widmer, J.; Saxena, P.; Idrees, M.; Iqbal, S.; Kalloo, A.N.; Stavropoulos, S.N. EUS-guided biliary drainage by using a standardized approach for malignant biliary obstruction: Rendezvous versus direct transluminal techniques (with videos). Gastrointest. Endosc. 2013, 78, 734-741. [CrossRef] [PubMed]

58. Park, D.H.; Jeong, S.U.; Lee, B.U.; Lee, S.S.; Seo, D.W.; Lee, S.K.; Kim, M.H. Prospective evaluation of a treatment algorithm with enhanced guidewire manipulation protocol for EUS-guided biliary drainage after failed ERCP (with video). Gastrointest. Endosc. 2013, 78, 91-101. [CrossRef] [PubMed]

59. Kawakubo, K.; Isayama, H.; Kato, H.; Itoi, T.; Kawakami, H.; Hanada, K.; Ishiwatari, H.; Yasuda, I.; Kawamoto, H.; Itokawa, F.; et al. Multicenter retrospective study of endoscopic ultrasound-guided biliary drainage for malignant biliary obstruction in Japan. J. Hepatobiliary Pancreat. Sci. 2014, 21, 328-334. [CrossRef] [PubMed]

60. Gupta, K.; Perez-Miranda, M.; Kahaleh, M.; Artifon, E.L.; Itoi, T.; Freeman, M.L.; de-Serna, C.; Sauer, B.; Giovannini, M.; InEBD Study Group. Endoscopic ultrasound-assisted bile duct access and drainage: Multicenter, long-term analysis of approach, outcomes, and complications of a technique in evolution. J. Clin. Gastroenterol. 2014, 48, 80-87. [CrossRef] [PubMed]

61. Dhir, V.; Itoi, T.; Khashab, M.A.; Park, D.H.; Yuen Bun Teoh, A.; Attam, R.; Messallam, A.; Varadarajulu, S.; Maydeo, A. Multicenter comparative evaluation of endoscopic placement of expandable metal stents for malignant distal common bile duct obstruction by ERCP or EUS-guided approach. Gastrointest. Endosc. 2015, 81, 913-923. [CrossRef] [PubMed]

62. Kahaleh, M.; Perez-Miranda, M.; Artifon, E.L.; Sharaiha, R.Z.; Kedia, P.; Peñas, I.; De la Serna, C.; Kumta, N.A.; Marson, F.; Gaidhane, M.; et al. International collaborative study on EUS-guided gallbladder drainage: Are we ready for prime time? Dig. Liver. Dis. 2016, 48, 1054-1057. [CrossRef] [PubMed]

63. Tsuchiya, T.; Teoh, A.Y.B.; Itoi, T.; Yamao, K.; Hara, K.; Nakai, Y.; Isayama, H.; Kitano, M. Long-term outcomes of EUS-guided choledochoduodenostomy using a lumen-apposing metal stent for malignant distal biliary obstruction: A prospective multicenter study. Gastrointest. Endosc. 2018, 87, 1138-1146. [CrossRef] [PubMed]

64. Minaga, K.; Ogura, T.; Shiomi, H.; Imai, H.; Hoki, N.; Takenaka, M.; Nishikiori, H.; Yamashita, Y.; Hisa, T.; Kato, H.; et al. Comparison of the efficacy and safety of endoscopic ultrasound-guided choledochoduodenostomy and hepaticogastrostomy for malignant distal biliary obstruction: Multicenter, randomized, clinical trial. Dig. Endosc. 2019, 31, 575-582. [CrossRef] [PubMed] 
65. Dhindsa, B.S.; Mashiana, H.S.; Dhaliwal, A.; Mohan, B.P.; Jayaraj, M.; Sayles, H.; Singh, S.; Ohning, G.; Bhat, I.; Adler, D.G. EUS-guided biliary drainage: A systematic review and meta-analysis. Endosc. Ultrasound 2020, 9, 101-109.

66. Khashab, M.A.; El Zein, M.H.; Sharzehi, K.; Marson, F.P.; Haluszka, O.; Small, A.J.; Nakai, Y.; Park, D.H.; Kunda, R.; Teoh, A.Y.; et al. EUS-guided biliary drainage or enteroscopy-assisted ERCP in patients with surgical anatomy and biliary obstruction: An international comparative study. Endosc. Int. Open 2016, 4, E1322-E1327. [CrossRef] [PubMed]

67. Bukhari, M.; Kowalski, T.; Nieto, J.; Kunda, R.; Ahuja, N.K.; Irani, S.; Shah, A.; Loren, D.; Brewer, O.; Sanaei, O.; et al. An international, multicenter, comparative trial of EUS-guided gastrogastrostomy-assisted ERCP versus enteroscopy-assisted ERCP in patients with Roux-en-Y gastric bypass anatomy. Gastrointest. Endosc. 2018, 88, 486-494. [CrossRef]

68. Weilert, F.; Binmoeller, K.F.; Marson, F.; Bhat, Y.; Shah, J.N. Endoscopic ultrasound-guided anterograde treatment of biliary stones following gastric bypass. Endoscopy 2011, 43, 1105-1108. [CrossRef] 